\title{
Incidence of Heterotopic Ossification in Direct Anterior Approach to Total Hip Arthroplasty with use of Aspirin as Thromboembolic Prophylaxis
}

Paul Knapp, D.O. ${ }^{1}$ @, Ross Doehrmann, D.O. ', Sanar Yokhana, M.D. ${ }^{2}$, Syed Rizvi, BSc ${ }^{2}$, Judith Boura ${ }^{3}$, David Knesek, D.O. ${ }^{1}$

1 Orthopaedics, Ascension St John Hospital and Medical Center, ${ }^{2}$ Orthopaedics, Detroit Medical Center, ${ }^{3}$ Statistics, Ascension Providence

Keywords: heterotopic ossification, total hip arthroplasty, anterior approach total hip arthroplasty, total joint arthroplasty, post op complications, patient outcomes

https://doi.org/10.51894/001c.12263

Spartan Medical Research Journal

Vol. 5, Issue 1, 2020

\section{CONTEXT}

Heterotopic ossification (H.O.) is a common occurrence after total hip arthroplasty (THA) with significant potential clinical ramifications. Controversy still exists regarding the exact etiology of the disorder, including possible risk factors. Surgical technique, surgical approach, postoperative medication protocols and even thromboembolic prophylaxis have been implicated in the formation of H.O. Our study looked at one institution with a single surgeon performing direct anterior THA (DAA THA) in patients who received aspirin (ASA) as monotherapy for thromboembolic prophylaxis.

\section{METHODS}

Patients at a single institution who underwent DAA THA between 2015 and 2019 were identified by CPT code. 45 patients ultimately met inclusion criteria. Postoperative radiographs were analyzed retrospectively for H.O. according to the Brooker classification. Several patient characteristics and comorbidities were statistically analyzed using Chi-square tests, Fisher Exact tests, Wilcox rank sum tests, and Pearson correlation.

\section{RESULTS}

12 patients (26.7\%) were found to have heterotopic ossification (67\% Class 1, 8\% Class 2 , $25 \%$ Class 3 , and $0 \%$ Class 4 ); with a median follow up of 35 weeks (range: $12-96$ ). $25 \%$ of these patients received ASA $325 \mathrm{mg}$ BID while $75 \%$ received ASA 81 BID. No statistical differences in development of H.O. were detected among age, gender, BMI, sex, race, diabetes, or NSAID use in the post-operative interval. There were significantly more smokers in the H.O. group (50\% vs. 9\%, p<0.006).

\section{CONCLUSIONS}

Our analysis aimed to quantify the incidence of H.O. with consistency in surgical approach and post-operative protocol. There have been few studies on this topic, and we believe it is very relevant with the increasing use of aspirin in the post-operative protocol for thromboembolic prophylaxis. Our retrospective analysis identified H.O. at rates similar to previous studies in DAA.

\section{INTRODUCTION}

In total hip arthroplasty (THA), the articulation of the proximal femur and acetabulum is resurfaced in order to provide pain relief and restore more normal mechanics/function of the hip joint. ${ }^{1}$ Following THA, a relatively common complication is the development of heterotopic ossification (HO). $\mathrm{HO}$ is the process of the soft tissues becoming ossified. ${ }^{2}$ The ossification represents primitive mesenchymal cells in the soft tissues being transformed into osteoblastic tissue. Further development of the tissue leads to the formation of mature lamellar bone. ${ }^{3} \mathrm{HO}$ occurs frequently in the femoral neck region, specifically adjacent to the greater trochanter, the area of the proximal femur that the abductor musculature attaches. Monitoring this pathology during clinicbased follow-up is paramount as it tends to progress over time. ${ }^{4}$

Some reported risk factors of HO in THA have included male gender, increased body mass index (BMI), history of HO, hypertrophic osteoarthritis, ankylosing spondylitis, diffuse idiopathic skeletal hyperostosis, Paget's disease, post-traumatic arthritis, rheumatoid arthritis, and decreased preoperative range of motion, and proliferative os- 
teoarthritis..$^{2,4-6}$ Other surgeon-controlled factors such as surgical approach, soft tissue trauma, and prolonged ischemia times have also been considered. ${ }^{7}$

Radiographic evidence of $\mathrm{HO}$ has been reported in up to $25-40 \%$ of THA's with as many as $10 \%$ of patients reporting symptoms affecting functional outcomes and range of motion. ${ }^{8}$ It is important for clinicians to monitor for clinical progression of these lesions as they may have detrimental effects on patient satisfaction and functional outcomes. ${ }^{9}$ Early symptoms of HO may include increasing pain, swelling and stiffness in the effected joint. ${ }^{10}$ Progression is commonly related to a decrease in range of motion on examination with continued pain complaints.

Laboratory studies may be used alongside radiographic and clinical evaluation to diagnose HO. Typically, these labs include a normal serum calcium and phosphorus level, which can help differentiate these lesions from other skeletal and/or endocrine disease processes. Alkaline phosphatase may also be elevated in the initial stages due to increased osteoblast (i.e., bone formation) activity, but typically returns to normal after the bone matures. ${ }^{10}$

Chemoprophylaxis against the formation of HO following THA is common practice among high risk patients. ${ }^{11}$ Prescribed medications include indomethacin, a nonselective cyclooxygenase COX-1 and COX-2 inhibitor, which is routinely administered at an oral dose of $75 \mathrm{mg}$. twice per day (BID) or $25 \mathrm{mg}$. three times per day (TID) for three to six weeks postoperatively. ${ }^{12}$ Other Nonsteroidal Anti-Inflammatory drugs (NSAID) and COX-2 inhibitors have also been studied for their effect on HO formation with satisfactory results. ${ }^{13}$ Radiation therapy is another mode of prophylaxis against $\mathrm{HO}$ formation with multiple studies claiming no significant difference compared to oral NSAID. ${ }^{14}$

Early stages of HO rarely require any surgical intervention. However, in select patients with substantial functional impairment operative excision may be necessary and helpful. While timing of surgical excision is still debated, there is evidence that patients with significant deficits who have not improved with conservative measures should be offered operative intervention. ${ }^{15}$

Surgeons routinely use Novel Oral Anti-Coagulants (NOAC) or NSAID as post-surgical thromboembolic prophylaxis for prevention of pulmonary embolism (PE) or deep venous thrombosis (DVT) in the post-operative period. These are serious complications of surgery leading to significant morbidity to patients. As more and more physicians transition to the use of Aspirin (ASA) alone for prophylaxis, we may appreciate a decrease in rates of $\mathrm{HO}$.

\section{PURPOSE OF STUDY}

Our study examined the incidence of $\mathrm{HO}$ at our institution with one surgeon who performed direct anterior approach total hip arthroplasties (DAA THA). DAA THA is a popular approach with a reported learning curve of up to 100 cases. ${ }^{16,17}$ There is also a potential for significant variation surgeon to surgeon when it comes to soft tissue handling, use of special tables/retractors, and post-operative management. ${ }^{11}$ The authors aimed to quantify the overall incidence of H.O. amongst our cohort and compare this to the rates in the literature. Risk factors for development of H.O. were al- so examined and analyzed in the study.

\section{METHODS}

Before data collection, IRB exempt determination was obtained from the Detroit Medical Center internal review board committee. Patients who had recived a DAA THA from $3 / 8 / 2016$ to $1 / 22 / 2019$ were included in the analytic sample. Additional inclusion criteria included: patient age 18 or older, minimum of three months postoperative follow up, and use of either ASA $325 \mathrm{mg}$. or ASA $81 \mathrm{mg}$. post-operatively for thromboembolic prophylaxis. Exclusion criteria included: patients who had received revision surgery, had prior hip surgery, infection after index procedure, or undergoing THA with any approach besides direct anterior.

The surgeon, (senior author DK) used a special table for each of his anterior hip patients, with a large C-arm for positioning of femoral and acetabular components. This surgeon was well beyond the stated learning curve (>100+ cases) for DAA THA. Dissection and all systematic releases for primary hips were consistent throughout the study period. A capsulotomy (opening of the anterior hip capsular tissue) was performed in each sample patient. An attempt to close the capsule tightly was performed at the conclusion of every case. Additionally, to evaluate contributing factors in the development of HO after DAA-THA, additional data points were collected on all patients who met inclusion criteria. Retrospective sociodemographic data such as age, gender, and race were also collected as well as clinical data regarding comorbidities such as diabetes, cardiovascular disease, osteoporosis, smoking status.

A manual medical record review was conducted by three upper level residents ( $\mathrm{PK}, \mathrm{RD}, \mathrm{SY})$ to investigate if administration of a NSAID was administered during the hospital stay; specifically, both drug type and dose were recorded. DVT prophylaxis, specifically the dose of ASA, was also recorded. Finally, HO was conducted by one senior resident (first author PK), using the Brooker Classification System. ${ }^{18}$ (Figures 1a-1c) Observing this system, Class 1 is described as islands of bone within the soft tissues about the hip. Class 2 includes bone spurs originating from the pelvis or proximal end of the femur, leaving at least $1 \mathrm{~cm}$. between opposing bone surfaces. Class 3 consists of bone spurs originating from the pelvis or proximal end of the femur, reducing the space between opposing bone surfaces to less than $1 \mathrm{~cm}$. Class 4 shows apparent bone ankylosis of the hip. ${ }^{19}$ Finally, if post-operative complications such as dislocation occurred this was included in our review of the EMR.

Our experienced statistician (fifth author JB) used $S A S$ for Windows ${ }^{\circledR}$, version 9.4 software for all study analyses. Categorical variables were examined with Chi-square tests where appropriate. Otherwise Fisher's Exact tests were used. Age, BMI and follow up are provided as means $+/-$ the standard deviation, followed by the minimum to maximum (range). Wilcoxon rank sum tests were used to analyze for possible relationship between these variables.

\section{RESULTS}

A total of 45 patients met inclusion criteria and were in- 


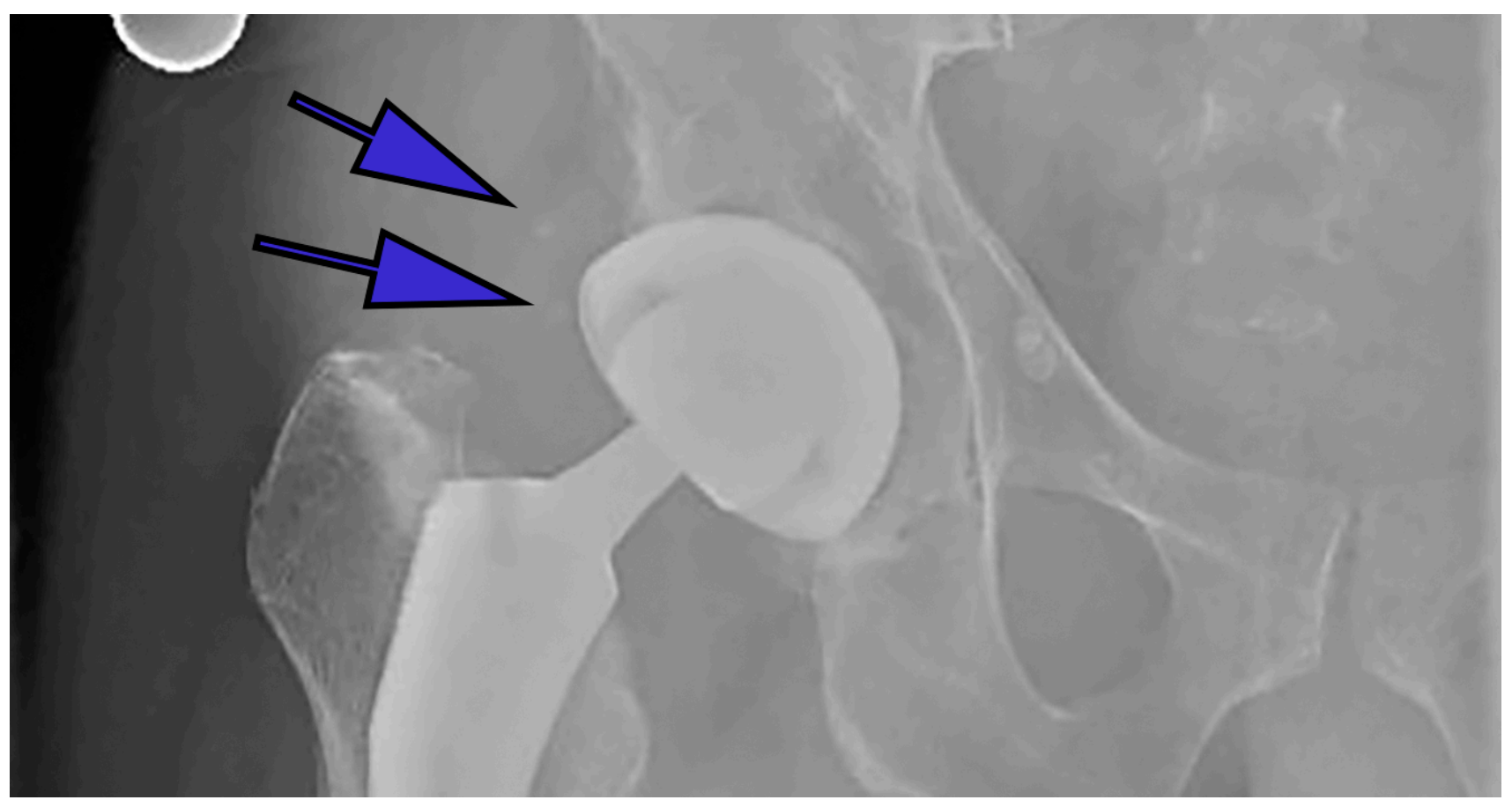

Figure 1(a): Anteroposterior (AP) radiographs of post-op total hip arthroplasties with differing classes of HO according to the Brooker classification

Class 1: showing small islands of bone within the soft tissue

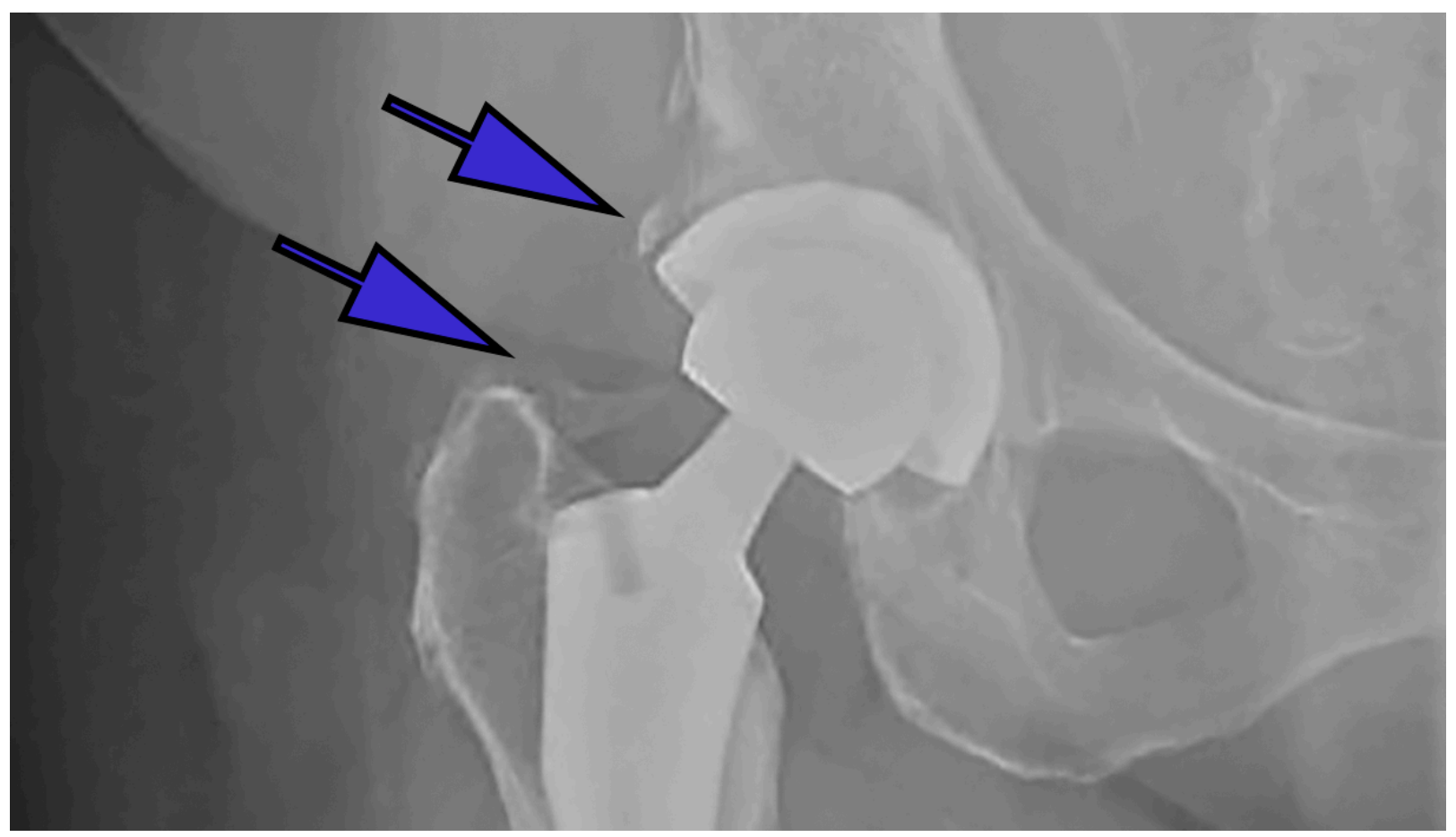

Figure 1(b): Anteroposterior (AP) radiographs of post-op total hip arthroplasties with differing classes of $\mathrm{HO}$ according to the Brooker classification

Class 2: bone growth from the femur and pelvis leaving $>1 \mathrm{~cm}$ from end to end

cluded for analysis. All surgeries were performed by one surgeon at the single hospital setting with dates ranging from $3 / 8 / 2016$ to $1 / 22 / 2019$. There were 23 (51\%) female and $22(49 \%)$ male patients with an average age of $58(+/-9)$ years. Mean BMI of the cohort was 29 (+/- 4.65). A total of
38 patients identified as Caucasian (85\%), 12 patients identified as African American (13\%) and five patients were of other racial background (2\%). The median follow-up time for final radiographic analysis was 35 weeks from the date of index surgery with no significant difference in length of 


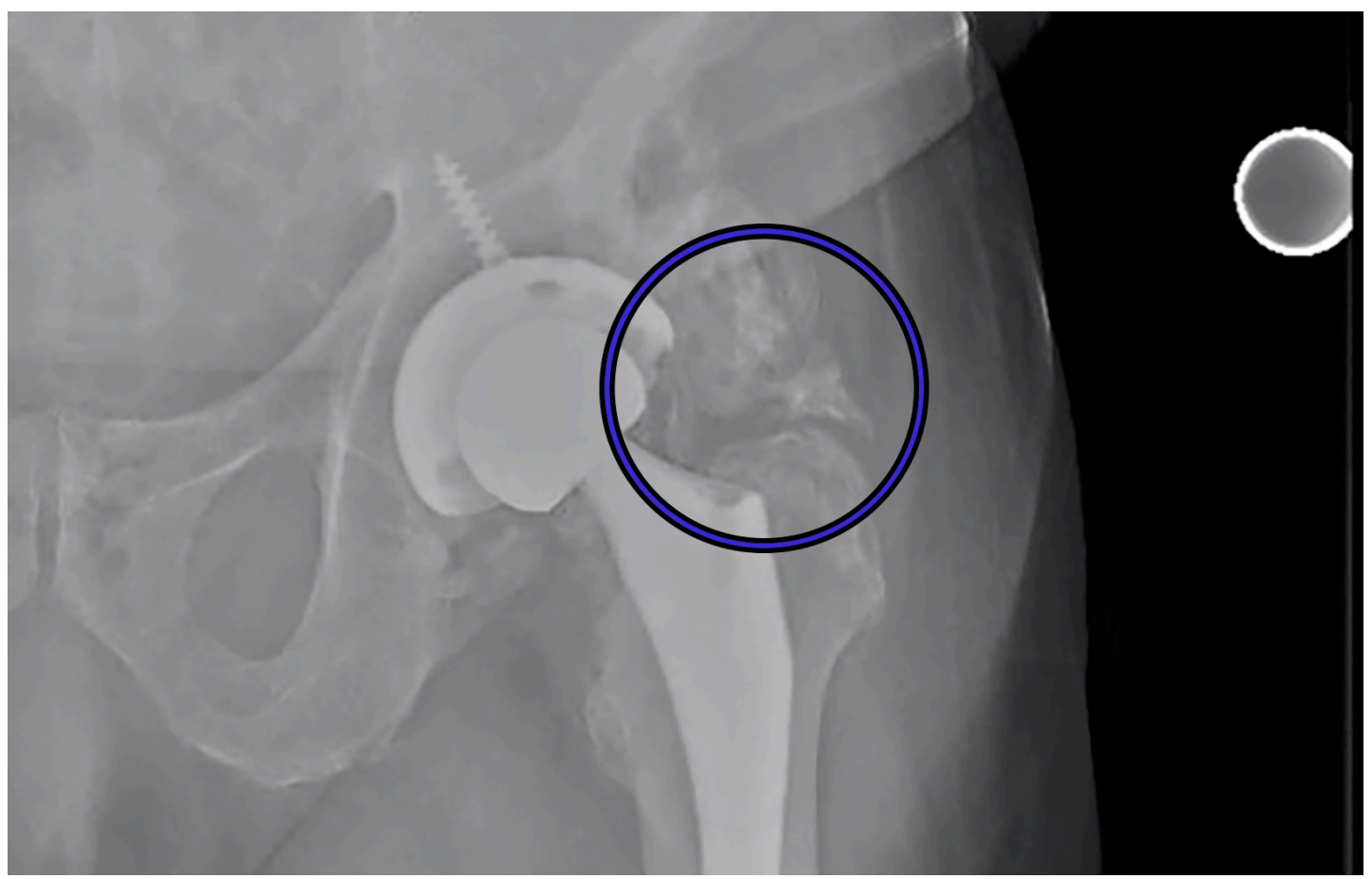

Figure 1(c): Anteroposterior (AP) radiographs of post-op total hip arthroplasties with differing classes of HO according to the Brooker classification

Class 3: bone growth extending from femur and pelvis with $<1 \mathrm{~cm}$ between ends

final follow up found between the patients who developed $\mathrm{HO}$ and those who did not $(\mathrm{P}=0.64)$.

The incidence of HO in our study was 12/45 (26.67\%). Class I HO was found in eight patients (66.67\%), Class II in one patient $(8.33 \%)$, Class III in three patients $(25 \%)$, and zero patients with Class IV. Postoperative NSAID use as needed was noted in 29 (64.4\%) patients and there was no statistically significant relationship noted $(\mathrm{P}=1.00)$ between the development of $\mathrm{HO}(8 / 12 ; 66.7 \%)$ and not developing HO $(21 / 33 ; 63.6 \%)$. The mean BMI for those who developed HO was $29.3(+/-4.7)$ while those without had an average BMI of 29.7 (+/- 4.7) with no statistically significant difference noted between groups $(\mathrm{P}=0.98)$.

Rates of pre-operative smoking status did reach statistical significance between the two sample subgroups with three (9.1\%) of those patients without HO reporting history of smoking while six (50\%) of those who did develop HO reporting a positive smoking history $(\mathrm{P}=0.006)$. There were no significant differences found between the two subgroups with regards to age, sex, race, or diabetes (Table 1).

\section{DISCUSSION}

The numerous surgical approaches for total hip arthroplasty have been a dominant topic in the literature with the more recent popularity of the direct anterior approach to the hip. ${ }^{20}$ Selected outcome indicators have included postoperative recovery time, narcotic use, and component malalignment as the focus of comparison studies between all approaches. ${ }^{21,22}$ There have been few studies on HO and the associated risk factors and prevention strategies. In this study, our goal was to combine variables studied in associ- ation with heterotopic ossification in the literature, which included surgical approach, use of ASA for thromboembolic prophylaxis, and surgical technique.

We found no significant difference between the two subgroups with regards to age, sex, race, or diabetes. We acknowledge that our sample may have failed to afford us an adequate level of statistical power to detect meaningful subgroup differences that may have been detected in a larger sample. We were, however, able to find a statistically significant difference in smoking rates between our two groups.

One might expect a decreased chance of HO in the smoking population due to the well-established negative/inhibitory effect of smoking on bone growth/healing. ${ }^{23,24}$ Studies of osteoblastic cells have shown both inhibition of protein synthesis as well as collagen formation with exposure to tobacco smoke. ${ }^{25}$ Clinical studies have shown conflicting results depending on the patient situation/clinical picture. In the setting of periprosthetic joint infection authors found an increased rate of HO in smokers, males, and patients with an increasing number of surgeries. ${ }^{26}$ In another, with a sample of military patients who underwent a traumatic amputation, there was no relationship found between smokers and the development of HO in matched samples. ${ }^{27}$ Literature on this relationship is certainly lacking.

In a 2014 study by Tippets et al, the authors investigated the incidence of $\mathrm{HO}$ in the direct anterior approach and found an overall incidence of $41.5 \%{ }^{28}$ In this study, there were two separate surgeons at independent hospitals included. Interestingly enough, they found a significant difference in the formation of $\mathrm{HO}$ between patients receiving ASA and Lovenox (25.7 v 47.5\%, respectively). ${ }^{28}$ In a 2010 
study by Cohn et al, a posterolateral approach was used exclusively, but similar results were found as patients receiving aspirin ASA had an incidence of $22.2 \%$, compared to the Coumadin group at $51.7 \%$, which was statistically significant. ${ }^{8}$

Coumadin, a vitamin $\mathrm{K}$ antagonist, can also be used for the prevention of venous thrombosis after orthopaedic surgery. ${ }^{29}$ Another mentioned pharmacologic therapy, Lovenox, is a low molecular weight heparin which can also be used in the prevention of DVT and PE after general and/ or orthopaedic surgery. ${ }^{30}$

The reason for potential improvement in outcomes with use of concomitant NSAIDs has previously been studied. ${ }^{31}$ Although a consensus has not been reached on the exact mechanism, there are numerous theories. In THA, there is the process of reaming and broaching of the femoral canal and acetabulum, which releases bone and its precursor cells into the surgical window. Prostaglandin-E2 is thought to be involved in the process of $\mathrm{HO}$, which explains the inhibition of this process with anti-inflammatory medications. ${ }^{11}$

Studies have shown that doses of indomethacin have been effective at preventing $\mathrm{HO}$, with the optimal dosage being a topic of controversy. ${ }^{32-34}$ Radiation therapy is another common method of prophylaxis. In a randomized trial by Liu et al, the authors showed a decrease in $\mathrm{HO}$ formation in patients receiving 700cGy compared to doses of 400cGy without any increase in wound complications. 35

In addition to the introduction of bone progenitor cells and growth factors (early stage cells and induction factors that lead to new bone formation) into the soft tissues from reaming, there is the possibility that the handling and dissection of soft tissues is the main culprit in HO formation. This theory was supported in 2001 by Sneath et al who found that immediate pulse lavage (repetitive pressurized irrigation) with $3 \mathrm{~L}$ of normal saline did not decrease the rate of $\mathrm{HO}$ when compared to $500 \mathrm{~mL}$ of irrigation with a syringe. 36

The idea that surgical handling of the tissues results in $\mathrm{HO}$ is especially interesting when approaches to the hip are discussed. In a retrospective case control study by Hurlimann et al, the incidence of HO was compared between approaches with 134 consecutive patients undergoing THA. Rates of HO were $31.3 \%$ (standard anterolateral), $20.9 \%$ (standard post lateral), 29.1\% (minimally invasive anterior approach), and $18.7 \%$ (minimally invasive anterolateral). ${ }^{37}$ Unfortunately, there was no mention of post-op NSAID use or what thromboembolic prophylaxis was used during their study. Another study by Alijanipour et al, showed rates of $\mathrm{HO}$ at $36.1 \%$ for direct lateral and $\mathbf{1 9 . 4 \%}$ for direct anterior indicating low rates of $\mathrm{HO}$ in the anterior approach. 38

The variability between surgeons and the extent of their soft tissue releases and exposures can significantly impact the amount of damage to surrounding tissues. ${ }^{38}$ This is the reason we aimed to use one surgeon in our analyses. Our rate of $\mathrm{HO}$ in the DAA (26.7\%) was similar to rates described in the literature $28,37,38$ and we were able to keep these surgical variables constant.

One limitation of our study was that our institution's post-op DVT prophylaxis changed in August 2016 when the protocol changed from ASA $325 \mathrm{mg}$. BID to ASA $81 \mathrm{mg}$. BID. Although this introduced some level of variability, we be- lieve these differing dosages of the same medication would have a minimal effect on the outcomes of this study. It has since been shown that in regard to thromboembolic prophylaxis, there may be no difference in development of symptomatic DVT after THA between low dose and full dose ASA. ${ }^{39}$ Similarly, we hypothesized that the small change in dose would not affect the rates of $\mathrm{HO}$, which was supported in our study $(p=0.62)$

All patients who received other modes of prophylaxis were excluded from the study. Our median follow up time was 35 weeks (range:12 - 122). This was largely due to the fact that the primary surgeon has follow up clinic visits at two, six, 12 weeks and one year after THA. At the 12-week visit, radiographs are generally performed and evaluated. Patients are then asked to follow up at one year for further evaluation, but per protocol, radiographs were only obtained if there were any concerns about the prosthesis clinically. This occasionally led to availability of radiographs at the 12-week office visit, but none at the one-year visit, which could explain the average follow up of 8-9 months. It is important to consider that HO typically arises within six weeks post-operatively but can progress until about six months post-operatively. ${ }^{18}$

While there were no NSAIDs prescribed at time of discharge from the hospital, there was an order for the NSAID Ketorolac/Toradol 15mg every six hours as needed in 29 (64.4\%) patients while in the hospital. The majority of our sample patients received one dose of this medication in the immediate post-op period and did not require additional doses. Patients were not prescribed any NSAIDs at the time of discharge and there were no prescriptions given for NSAIDs from our office in the post-operative period. There was no difference in incidence of $\mathrm{HO}$ found between the patients receiving NSAIDs as needed while inpatient and those who did not, indicating that this small dose of PRN (as needed) medication was not likely clinically significant.

A major strength of our study was the use of one fellowship-trained arthroplasty surgeon who exclusively uses the DAA for his total hip arthroplasties. This reduces the amount of variability when it comes to the approach and handling of the soft tissue. It is our understanding that there have not been any studies looking exclusively at direct anterior approach with a standardized post-operative protocol including thromboembolic ASA prophylaxis.

\section{CONCLUSIONS}

This is the first apparent study to examine the incidence of HO formation after DAA THA using exclusively ASA as DVT/PE prophylaxis. The incidence of $\mathrm{HO}$ was $26.7 \%$ and does not appear to be influenced by demographic factors including age, sex, race, or diabetes. Based on these results, there may be a correlation between smoking and HO formation after THA, although further research into this relationship is needed. Additionally, post-op NSAID use as needed while inpatient did not appear to influence HO formation following THA in this patient sample. In conclusion, the incidence of HO after DAA THA with post-op aspirin DVT/PE prophylaxis in our study is similar to that published in other research, although there remains a need for larger-sample prospective studies examining this topic. 
Table 1: Demographic data and variables of interest with and without HO

\begin{tabular}{|c|c|c|c|}
\hline & No HON=33 & Presence of $\mathrm{HON}=12$ & p-value \\
\hline \multicolumn{4}{|l|}{ Age } \\
\hline $\begin{array}{l}\text { Mean+/- Standard } \\
\text { Deviation (median) }\end{array}$ & $57+/-11(57)$ & 44 to 76 & \multirow[t]{2}{*}{0.97} \\
\hline Minimum to Maximum & 30 to 75 & $58+/-9(59)$ & \\
\hline \multicolumn{4}{|l|}{ BMI } \\
\hline Mean +/- SD (median) & $29.7+/-4.7(29)$ & $29.3+/-4.7(30.5)$ & \multirow{2}{*}{0.98} \\
\hline Minimum to Maximum & 21.6 to 39.6 & 20.6 to 35.2 & \\
\hline Males & $14(42.4 \%)$ & $8(66.7 \%)$ & 0.19 \\
\hline \multicolumn{4}{|l|}{ Race } \\
\hline African American & $3(9.1 \%)$ & $3(25 \%)$ & \multirow{3}{*}{0.50} \\
\hline Caucasian & $29(87.9 \%)$ & $9(75 \%)$ & \\
\hline Other & $1(3.0 \%)$ & 0 & \\
\hline Diabetes & $1(3.0 \%)$ & 0 & 1.00 \\
\hline $\begin{array}{l}\text { Preoperative } \\
\text { Smoking Status (+) }\end{array}$ & $3(9.1 \%)$ & $6(50 \%)$ & 0.006 \\
\hline \multicolumn{4}{|l|}{ DVT/PE PPx } \\
\hline ASA $325 \mathrm{mg}$. BID & $14(42.4 \%)$ & $3(25 \%)$ & \multirow{2}{*}{0.62} \\
\hline ASA $81 \mathrm{mg}$. BID & $19(57.6 \%)$ & $9(75 \%)$ & \\
\hline $\begin{array}{l}\text { As Needed NSAID } \\
\text { use post-op }\end{array}$ & $21(63.6 \%)$ & $8(66.7 \%)$ & 1.00 \\
\hline \multicolumn{4}{|l|}{ Follow up (\# of weeks) } \\
\hline Median (25 th, $75^{\text {th }}$ ) & $35(13,52)$ & $35(13,61)$ & \multirow[b]{2}{*}{0.64} \\
\hline Minimum to Maximum & 12 to 122 & 12 to 96 & \\
\hline
\end{tabular}

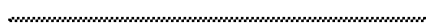

\section{FUNDING}

The authors report no external funding source for this study.

\section{CONFLICT OF INTEREST}

The authors declare no conflict of interest.

Submitted: December 15, 2019 EST, Accepted: March 15, 2020 EST

This is an open-access article distributed under the terms of the Creative Commons Attribution 4.0 International License (CCBY-4.0). View this license's legal deed at http://creativecommons.org/licenses/by/4.0 and legal code at http://creativecommons.org/licenses/by/4.0/legalcode for more information. 


\section{REFERENCES}

1. Mirza SB, Dunlop DG, Panesar SS, Naqvi SG, Gangoo S, Salih S. Basic Science Considerations in Primary Total Hip Replacement Arthroplasty. TOORTHJ. 2010;4(1):169-180. doi:10.2174/187432500 $\underline{1004010169}$

2. Kaplan FS, Hahn GV, Zasloff M.A. Heterotopic ossification: Two rare forms and what they can teach us. J Am Acad Orthop Surg. 1994;2:288-296.

3. Erens G. Complications of total hip arthroplasty. UpToDate. October 2017. https://www.uptodate.com/c ontents/complications-of-total-hip-arthroplasty?sour ce=history widget\#H38.

4. Iorio R, Healy WL. Heterotopic ossification after hip and knee arthroplasty: Risk factors, prevention, and treatment. Journal of the American Academy of Orthopaedic Surgeons. 2002;10(6):409-416. doi:10.543 5/00124635-200211000-00005

5. Ahrengart L. Periarticular heterotopic ossification after total hip arthroplasty: Risk factors and consequences. Clin Orthop. 1991;263:49-58.

6. Eggli S, Woo A. Risk factors for heterotopic ossification in total hip arthroplasty. Archives of Orthopaedic and Trauma Surgery. 2001;121(9):531-535. doi:10.1007/s004020100287

7. Firoozabadi R, O’Mara TJ, Swenson A, Agel J, Beck JD, Routt M. Risk factors for the development of heterotopic ossification after acetabular fracture fixation. Clin Orthop Relat Res. 2014;472(11):3383-3388. doi:10.1007/s11999-014-37 19-2

8. Cohn RM. Heterotopic Ossification Is Less after THA in Patients Who Receive Aspirin Compared to Coumadin. Bulletin of the NYU Hospital for Joint Diseases. 2010;68(4):266-272.

9. Neal B. Effects of Heterotopic Bone Formation on Outcome after Hip Arthroplasty. ANZ J Surg. 2003;73(6):422-426. doi:10.1046/i.1445-2197.2003.02 $\underline{647 . x}$

10. Kaplan FS, Glaser DL, Hebela N, Shore EM. Heterotopic Ossification. Journal of the American Academy of Orthopaedic Surgeons. 2004;12(2):116-125. doi:10.5435/00124635-20040300 0-00007
11. Board TN, Karva A, Board RE, Gambhir AK, Porter ML. The Prophylaxis and Treatment of Heterotopic Ossification Following Lower Limb Arthroplasty. The Journal of Bone and Joint Surgery British volume. 2007;89-B(4):434-440. doi:10.1302/0301-620x.89b4.1 $\underline{8845}$

12. Le Duff MJ, Takamura KB, Amstutz HC. Incidence of heterotopic ossification and effects of various prophylactic methods after hip resurfacing. Bull NYU Hosp Jt Dis. 2011;69(Suppl 1):S36-41.

13. Vasileiadis GI, Sioutis IC, Mavrogenis AF, Vlasis K, Babis GC, Papagelopoulos PJ. COX-2 inhibitors for the prevention of heterotopic ossification after THA. Orthopedics. 2011;34(6):467-472. doi:10.3928/014774 47-20110427-23

14. Pakos EE, Ioannidis JPA. Radiotherapy vs. nonsteroidal anti-inflammatory drugs for the prevention of heterotopic ossification after major hip procedures: A meta-analysis of randomized trials. International Journal of Radiation Oncology*Biology*Physics. 2004;60(3):888-895. doi:1 0.1016/j.ijrobp.2003.11.015

15. Lee EK, Namdari S, Hosalkar HS, Keenan MA, Baldwin KD. Clinical results of the excision of heterotopic bone around the elbow: A systematic review. Journal of Shoulder and Elbow Surgery. 2013;22(5):716-722. doi:10.1016/i.jse.2012.11.020

16. Van Den Eeden Y, Van Den Eeden F. Learning Curve of Direct Anterior Total Hip Arthroplasty: A Single Surgeon Experience. Acta Orthopaedica Belgica. 2018;84(3):321-330.

17. Hartford JM, Bellino MJ. The Learning Curve for the Direct Anterior Approach for Total Hip Arthroplasty: A Single Surgeon's First 500 Cases. HIP International. 2017;27(5):483-488. doi:10.5301/hipin t.5000488

18. Brooker AF, Bowerman JW, Robinson RA, Riley LHJR. Ectopic Ossification Following Total Hip Replacement: Incidence and a method of classification. The Journal of Bone \& Joint Surgery. 1973;55(8):1629-1632. doi:10.2106/00004623-197355 080-00006

19. Hug KT, Alton TB, Gee AO. In Brief: Classifications in Brief: Brooker Classification of Heterotopic Ossification After Total Hip Arthroplasty. Clin Orthop Relat Res. 2015;473(6):2154-2157. doi:1 0.1007/s11999-014-4076-x 
20. Rachbauer F, Kain MS, Leunig M. The history of the anterior approach to the hip. Orthop Clin N Am. 2009;40(311).

21. Finch DJ, Martin BI, Franklin PD, Magder LS, Pellegrini VDJr. Patient-Reported Outcomes Following Total Hip Arthroplasty: A Multicenter Comparison Based on Surgical Approaches. The Journal of Arthroplasty. 2020;35(4):1029-1035.e3. do i:10.1016/i.arth.2019.10.017

22. Zawadsky MW, Paulus MC, Murray PJ, Johansen MA. Early Outcome Comparison Between the Direct Anterior Approach and the Mini-Incision Posterior Approach for Primary Total Hip Arthroplasty: 150 Consecutive Cases. The Journal of Arthroplasty. 2014;29(6):1256-1260. doi:10.1016/j.arth.2013.11.013

23. Castillo RC, Bosse MJ, MacKenzie EJ, Patterson BM. Impact of Smoking on Fracture Healing and Risk of Complications in Limb-Threatening Open Tibia Fractures. Journal of Orthopaedic Trauma. 2005;19(3):151-157. doi:10.1097/00005131-20050300 $\underline{0-00001}$

24. Raikin SM, Landsman JC, Alexander VA, Froimson MI, Plaxton NA. Effect of nicotine on the rate and strength of long bone fracture healing. Clinical Orthopaedics and Related Research. 1998;353:231-237. doi:10.1097/00003086-199808000-00027

25. Gullihorn L, Karpman R, Lippiello L. Differential effects of nicotine and smoke condensate on bone cell metabolic activity. Journal of Orthopaedic Trauma. 2005;19(1):17-22. doi:10.1097/00005131-20050100 $\underline{0-00004}$

26. Rosteius T, Rausch V, Pätzholz S, et al. Incidence and Risk Factors for Heterotopic Ossification Following Periprosthetic Joint Infection of the Hip. Arch Orthop Trauma Surg. 2019;139(9):1307-1314. do i:10.1007/s00402-019-03215-6

27. Lewis PC, Camou E, Wofford K. The Impact of Cigarette Smoking on the Formation of Heterotopic Ossification Among Service Members With a Traumatic Amputation. Military Medicine. 2017;182(5):e1742-e1748. doi:10.7205/milmed-d-1 6-00350

28. Tippets DM, Zaryanov AV, Vincent Burke W, et al. Incidence of Heterotopic Ossification in Direct Anterior Total Hip Arthroplasty: A Retrospective Radiographic Review. The Journal of Arthroplasty. 2014;29(9):1835-1838. doi:10.1016/j.arth.2014.04.027

29. Kuruvilla M, Gurk-Turner C. A Review of Warfarin Dosing and Monitoring. Baylor University Medical Center Proceedings. 2001;14(3):305-306. doi:10.1080/0 $\underline{8998280.2001 .11927781}$
30. Noble S, Spencer CM. Enoxaparin. Drugs. 1998;56(2):259-272. doi:10.2165/00003495-19985602 $\underline{0-00013}$

31. Fransen M, Neal B. Non-steroidal antiinflammatory drugs for preventing heterotopic bone formation after hip arthroplasty. Cochrane Database Syst Rev. 2004;3:CD001160.

32. Ahrengart L, Lindgren U, Reinholt FP. Comparative study of the effects of radiation, indomethacin, prednisilone and ethane-1-hydroxy-1, 1-disphonate (EHDP) in the prevention of ectopic bone formation. Clin Orthop. 1988;229:265-273.

33. Burd TA, Lowry KJ, Anglen JO. Indomethacin compared with localized irradiation for the prevention of heterotopic ossification following surgical treatment of acetabular fractures. J Bone Joint Surg [Am]. 2001;83-A:1783-1788.

34. Matta JM, Siebenrock KA. Does indomethacin reduce heterotopic bone formation after operations for acetabular fractures?: A prospective randomised study. J Bone Joint Surg [Br]. 1997;79-B:959-963.

35. Liu JZ, Frisch NB, Barden RM, Rosenberg AG, Silverton CD, Galante JO. Heterotopic Ossification Prophylaxis After Total Hip Arthroplasty: Randomized Trial of 400 vs 700 CGy. The Journal of Arthroplasty. 2017;32(4):1328-1334. doi:10.1016/j.art $\underline{\text { h.2016.10.030 }}$

36. Sneath RJS, Bindi FD, Davies J, Parnell EJ. The Effect of Pulsed Irrigation on the Incidence of Heterotopic Ossification after Total Hip Arthroplasty. The Journal of Arthroplasty. 2001;16(5):547-551. doi:1 0.1054/arth.2001.23562

37. Hürlimann M, Schiapparelli F-F, Rotigliano N, Testa E, Amsler F, Hirschmann MT. Influence of Surgical Approach on Heterotopic Ossification after Total Hip Arthroplasty - Is Minimal Invasive Better? A Case Control Study. BMC Musculoskelet Disord. 2017;18(1). doi:10.1186/s12891-017-1391-x

38. Alijanipour P, Patel RP, Naik TU, Parvizi J. Heterotopic Ossification in Primary Total Hip Arthroplasty Using the Direct Anterior vs Direct Lateral Approach. The Journal of Arthroplasty. 2017;32(4):1323-1327. doi:10.1016/j.arth.2016.11.030

39. Faour M, Piuzzi NS, Brigati DP, et al. No Difference Between Low- and Regular-Dose Aspirin for Venous Thromboembolism Prophylaxis After THA. Clinical Orthopaedics and Related Research. 2019;477(2):396-402. doi:10.1097/corr.000000000000 $\underline{0613}$ 